\title{
Appendectomy Hospital Stay: No Difference in Obese Adult or Pediatric Patient Length of Stay Compared to Nonobese Patients
}

\author{
Eric Lorio, MD, ${ }^{1}$ David H. Ballard, MD, ${ }^{2}$ Elizabeth Guarisco, MD, ${ }^{1}$ James Hughes, MD, ${ }^{3}$ Forrest D. Griffen, MD, ${ }^{4}$ \\ Navdeep S. Samra, MD, FACS ${ }^{4}$ \\ ${ }^{1}$ Department of Internal Medicine, University of Texas Health Science Center at San Antonio, San Antonio, TX ${ }^{2}$ Department of Radiology, \\ Mallinckrodt Institute of Radiology, Washington University School of Medicine, St. Louis, MO ${ }^{3}$ Department of Anesthesiology, West Virginia \\ University, Morgantown, WV ${ }^{4}$ Department of Surgery, Louisiana State University School of Medicine-Shreveport, Shreveport, LA
}

\begin{abstract}
Background: Studies of adult and pediatric patients undergoing appendectomy have reported variable outcomes and operative metrics related to the effect of obesity. The purpose of this study was to investigate the effect of obesity in adult and pediatric patients undergoing appendectomy at our institution.

Methods: This single-center retrospective study evaluated the relationship between length of hospital stay for appendectomy and body mass index (BMI). Data obtained from the electronic medical record included age, sex, weight, height, BMI, the number of hours the patient experienced symptoms prior to presentation to the emergency room, the number of hours the patient was admitted prior to surgery, the number of hours of hospital admission after surgery, perforated appendix, preoperative comorbidities, and evidence of preoperative sepsis.

Results: During the 3-year study period, 118 adults and 38 children who underwent appendectomy composed the study groups. Patients were stratified by obese and nonobese, with obesity defined as BMI $\geq 30.0 \mathrm{~kg} / \mathrm{m}^{2}$. In adults, we found no significant difference between length of stay in obese $(n=45)$ and nonobese $(n=73)$ patients $(79.6 \pm 65.5$ hours vs $101.6 \pm 123.0$ hours; $P=0.21)$. In children, we found no significant difference between length of stay in obese $(n=9)$ and nonobese $(n=29)$ patients $(92.9 \pm 64.6$ hours vs $109.0 \pm 93.5$ hours; $P=0.54$ ).
\end{abstract}

Conclusion: Obesity did not affect length of stay in adults and children who underwent appendectomy in the present series.

Keywords: Appendectomy, body mass index, inpatients, length of stay, obesity, postoperative complications

Address correspondence to Navdeep S. Samra, MD, FACS, Department of Surgery, Louisiana State University School of Medicine-Shreveport, 1501 Kings Hwy., Shreveport, LA 71130. Tel: (318) 675-6355. Email: nsamra@lsuhsc.edu

\section{INTRODUCTION}

Appendectomy is one of the most common surgical procedures worldwide, whether performed for management of acute appendicitis or as an addition to a larger abdominal surgery. ${ }^{1}$ In the United States, approximately 200,000 appendectomies are performed annually. ${ }^{1}$ As such, patients undergoing appendectomy represent a sizable proportion of the general surgery patient population, and obesity may be an important factor in determining patient morbidity related to appendectomy performed for management of acute appendicitis.

Albeit not specific to appendectomy, studies suggest that high body mass index (BMI) is positively associated with in-hospital mortality and increased length of stay (LOS). ${ }^{2,3}$ Akinyemiju et al concluded that higher BMI was associated with increased risk of mortality and longer hospital stay in a cohort of more than 800,000 patients admitted for various medical and cancer-related diagnoses. ${ }^{2}$ Similarly, Lewis et al found that obesity was associated with increased comorbid illness and with significantly longer intensive care unit and hospital LOS. ${ }^{3}$ However, in a cohort of 272 patients who underwent appendectomy, no significant differences were found in postoperative recovery, appendix perforation status, or mortality between obese and nonobese patients, and Towfigh et al recommended no change in appendicitis management for obese patients. ${ }^{4}$ A study of a large national pediatric database that compared patients who underwent appendectomy to patients undergoing other intestinal operations showed that obese appendectomy pediatric patients had significantly longer hospital LOS compared nonobese patients, but no significant difference in LOS was seen between obese and nonobese patients undergoing other intestinal operations. ${ }^{5}$ Other studies have reported worse outcomes in obese adults and longer operating times in obese adults and children. ${ }^{6-8}$ The purpose of this study was to investigate the effect of obesity in adult 


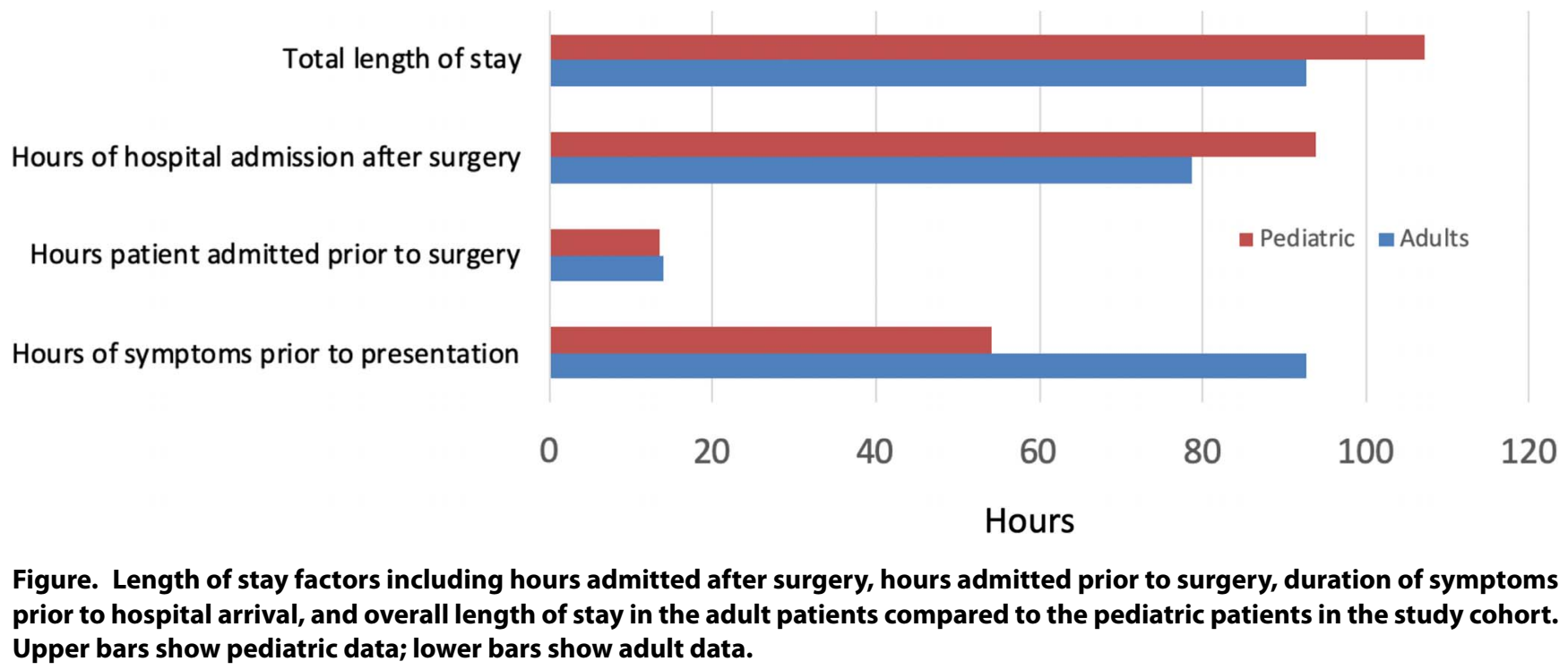

and pediatric patients undergoing appendectomy at our institution.

\section{METHODS}

This study is a retrospective analysis of adult and pediatric populations who had an appendectomy at our institution during a 3-year period. Review of electronic medical records was conducted after obtaining institutional review board approval. Obesity was defined as BMI $\geq 30.0 \mathrm{~kg} / \mathrm{m}^{2}$. Data obtained from the electronic medical record included age, sex, weight, height, BMI, the number of hours the patient experienced symptoms prior to presentation to the emergency room, the number of hours the patient was admitted prior to surgery, and the number of hours of hospital admission after surgery. International Classification of Diseases, Tenth Revision codes were used to identify perforation status of the appendix. All cases were also reviewed for evidence of appendix perforation by direct intraoperative visualization, preoperative comorbidities, and evidence of preoperative sepsis. Sepsis was defined as having at least 2 of the following in the presence of possible infection: central body temperature $>101^{\circ} \mathrm{F}\left(38.3^{\circ} \mathrm{C}\right)$ or $<96.8^{\circ} \mathrm{F}\left(36^{\circ} \mathrm{C}\right)$, heart rate $\geq 90 \mathrm{bpm}$, or respiratory rate $\geq 20$ breaths per minute. ${ }^{9}$ For comorbidities, each condition was recorded, and a comorbidity score $(0,1$, or $\geq 2)$ was created as the sum of the number of conditions per patient. BMI was stratified, and LOS was then compared between obese patients and nonobese patients.

A secondary analysis assessed whether preoperative admission time had an effect on postoperative admission time in the obese patient vs the nonobese patient. The purpose of this analysis was to determine if obese patients required more preoperative admission time to optimize for surgery. Obese patients were separated into groups: $<24$ hours preoperative admission time and $\geq 24$ hours preoperative admission time. Nonobese patients were separated using the same categories. Patients were also grouped according to number of comorbidities $(0,1$, or $\geq 2$ ). Postoperative LOS was subsequently compared.

Fisher exact test and $z$ score were used to calculate statistical values. Multivariable analysis was performed secon- darily, controlling for the potential confounders of BMI, sex, age, and number of comorbidities. $P$ values $<0.05$ were considered statistically significant.

\section{RESULTS}

The Figure shows the comparison in LOS and related factors for all adult and pediatric patients.

\section{Adult Patients}

We identified 118 adult patients who underwent appendectomy (Table 1). In the adult population, $58 \%$ were male, $42 \%$ were female, and their mean age was 38 years. Seventy-three patients (62\%) had a BMI $<30 \mathrm{~kg} / \mathrm{m}^{2}$, while 45 patients $(38 \%)$ had a $\mathrm{BMl} \geq 30 \mathrm{~kg} / \mathrm{m}^{2}$. A slight majority of female patients were obese $(n=26 ; 52 \%)$, whereas only $28 \%(n=19)$ of male patients were obese $(P=0.012)$. Obese patients had a similar appendix perforation rate $(18 \%)$ compared to nonobese patients $(14 \%)(P=0.700)$. We found no significant difference in the number of comorbidities between obese and nonobese patients $(P=0.42)$. Overall, 45 patients $(38 \%)$ had no comorbidities, 35 patients $(30 \%)$ had 1 comorbidity, and 38 patients (32\%) had 2 or more comorbidities.

We found no significant difference in length of time of symptoms before presentation to the emergency department, length of time patients were admitted prior to their surgery, or length of time patients were in the hospital after surgery was performed (Table 1).

LOS in adult patients was not affected by obesity at our institution (Table 2). In multivariate analysis, controlling for BMI, sex, age, and number of comorbidities, LOS in obese adult patients ( $79.6 \pm 65.5$ hours) was not significantly different compared to nonobese adult patients (101.6 \pm 123.0 hours) $(P=0.21)$. In multivariate analysis, none of the following was a significant predictor: the length of time of symptoms prior to emergency department presentation, preoperative admitted time, and postoperative admitted time $(P \geq 0.2$ in all comparisons).

When comparing patients receiving $<24$ hours of inpatient care preoperatively with patients receiving $\geq 24$ hours preoperatively, we found no significant change in the 
Table 1. Adult Patient Characteristics, Overall and by Body Mass Index (BMI) Classification

\begin{tabular}{|c|c|c|c|c|}
\hline Variable & $\begin{array}{c}\text { All Patients, } \\
\quad n=118\end{array}$ & $\begin{array}{c}\text { Nonobese, } \\
\text { BMI }<30 \mathrm{~kg} / \mathrm{m}^{2}, \\
\mathrm{n}=73\end{array}$ & $\begin{array}{c}\text { Obese, } \\
\text { BMI } \geq 30 \mathrm{~kg} / \mathrm{m}^{2}, \\
n=45\end{array}$ & $P$ Value \\
\hline Age, years, mean & 38 & 37 & 40 & 0.36 \\
\hline Sex & & & & 0.012 \\
\hline Female $^{a}$ & 50 & $24(48)$ & $26(52)$ & \\
\hline Male $^{a}$ & 68 & $49(72)$ & $19(28)$ & \\
\hline Perforated appendix & $18(15)$ & $10(14)$ & $8(18)$ & 0.700 \\
\hline Comorbidities & & 1.2 (mean) & 1.2 (mean) & 0.42 \\
\hline 0 & $45(38)$ & $26(36)$ & $19(42)$ & \\
\hline 1 & $35(30)$ & $25(34)$ & $10(22)$ & \\
\hline$\geq 2$ & $38(32)$ & $22(30)$ & $16(36)$ & \\
\hline Hours patient experienced symptoms prior to presentation, mean & 92.6 & 39.3 & 54.1 & 0.26 \\
\hline Hours patient admitted prior to surgery, mean & 14.0 & 15.8 & 11.2 & 0.19 \\
\hline Hours of hospital admission after surgery, mean & 78.6 & 85.5 & 67.5 & 0.28 \\
\hline
\end{tabular}

apercentages are calculated across the row and not by column.

Note: Data are presented as n (\%) unless otherwise indicated.

postoperative duration of inpatient admission for obese vs nonobese patients regardless of the number of comorbidities ( $P>0.05$ in all comparisons). Comparing $<24$ hours vs $\geq 24$ hours preoperatively, we found no significant difference in proportion of perforated appendix, sepsis, or mean number of comorbidities ( $P>0.05$ in all comparisons) between obese and nonobese patients. However, duration of inpatient admission preoperatively was 11.3 hours longer for patients with one or more comorbidities compared to patients without a comorbidity when controlling for BMI, sex, and age $(P=0.015)$

\section{Pediatric Patients}

We identified 38 pediatric patients who had appendectomies during the study period, 23 males $(61 \%)$ and 15 females $(39 \%)$ with a mean age of 9 years (Table 3 ). Nine patients $(24 \%)$ were obese. Most pediatric patients had no comorbidities (76\%). A greater percentage of the pediatric patients had a perforated appendix (26\%) compared to adults (15\%).

We observed a significant difference in the duration of experiencing symptoms before presentation to the emergency department $(P=0.015)$, with the obese population presenting after a mean of 28.1 hours of symptoms and the nonobese population presenting at a mean of 62.3 hours. We found no significant difference in the number of hours a pediatric patient spent admitted preoperatively $(P=0.25)$ or postoperatively $(P=0.78)$ between obese and nonobese patients.
We also noted no difference in the number of comorbidities $(P=0.45)$ between obese and nonobese pediatric patients. Obese patients were found to have a similar perforation rate when compared to nonobese patients $(P=0.25)$.

We found no significant difference in the total LOS between obese and nonobese pediatric patients $(P=0.54)$ (Table 2). Stratifying all patients-obese and nonobesewho received $<24$ hours vs $\geq 24$ hours of inpatient care preoperatively, we found no significant difference in the proportion of perforated appendix, sepsis, or mean number of comorbidities ( $P>0.05$ in all comparisons).

\section{DISCUSSION}

In this study, we found no difference in LOS between obese and nonobese patients receiving appendectomy in either the adult or pediatric subgroup. Secondary observations included (1) a significantly higher incidence of obese adult female patients vs obese adult male patients $(P=0.012)$, (2) an increased length of inpatient hospitalization preoperatively in adult patients with comorbidities when controlling for all variables $(P=0.015)$, and (3) a significant difference between the obese and the nonobese pediatric patients in the duration of experiencing symptoms before presentation to the emergency department $(P=0.015)$.

The high proportion of adult obese female patients in part may reflect the rising incidence of female obesity in the United States. ${ }^{10}$ Although Ballard et al did not investigate

Table 2. Hospital Length of Stay (LOS) in Adult $(n=118)$ and Pediatric $(n=38)$ Patients by Body Mass Index (BMI) Classification

\begin{tabular}{lccc}
\hline & Nonobese, BMI $<\mathbf{3 0 ~} \mathbf{~ g g} / \mathbf{m}^{\mathbf{2}}$ & Obese, BMI $\geq \mathbf{3 0} \mathbf{~ k g} / \mathbf{m}^{\mathbf{2}}$ & $\boldsymbol{P}$ Value \\
\hline Adult LOS, hours, mean \pm SD & $101.6 \pm 123.0$ & $79.6 \pm 65.5$ & 0.21 \\
Pediatric LOS, hours, mean \pm SD & $109.0 \pm 93.5$ & $92.9 \pm 64.6$ & 0.54 \\
\hline
\end{tabular}


Lorio, $E$

Table 3. Pediatric Patient Characteristics, Overall and by Body Mass Index (BMI) Classification

\begin{tabular}{|c|c|c|c|c|}
\hline Variable & $\begin{array}{c}\text { All Patients, } \\
n=38\end{array}$ & $\begin{array}{c}\text { Nonobese, } \\
\text { BMI }<30 \mathrm{~kg} / \mathrm{m}^{2}, \\
n=29\end{array}$ & $\begin{array}{c}\text { Obese, } \\
\text { BMI } \geq 30 \mathrm{~kg} / \mathrm{m}^{2}, \\
n=9\end{array}$ & $P$ Value \\
\hline Age, years, mean & 9 & 9 & 11 & 0.40 \\
\hline Sex & & & & 0.26 \\
\hline Female $^{a}$ & 15 & $10(67)$ & $5(33)$ & \\
\hline Male $\mathrm{a}^{\mathrm{a}}$ & 23 & $19(83)$ & $4(17)$ & \\
\hline Perforated appendix & $10(26)$ & $9(31)$ & $1(11)$ & 0.25 \\
\hline Comorbidities & & 0.11 (mean) & 0.2 (mean) & 0.45 \\
\hline 0 & $29(76)$ & $21(72)$ & $8(89)$ & \\
\hline 1 & $4(11)$ & $3(10)$ & $1(11)$ & \\
\hline$\geq 2$ & $5(13)$ & $5(17)$ & 0 & \\
\hline Hours patient experienced symptoms prior to presentation, mean & 54.2 & 62.3 & 28.1 & 0.015 \\
\hline Hours patient admitted prior to surgery, mean & 13.5 & 15.0 & 8.8 & 0.25 \\
\hline Hours of hospital admission after surgery, mean & 93.8 & 95.5 & 86.9 & 0.78 \\
\hline
\end{tabular}

apercentages are calculated across the row and not by column.

Note: Data are presented as n (\%) unless otherwise indicated.

appendectomy, their surgical study reported a higher incidence of obese female patients than male patients. ${ }^{11}$

Contrary to our findings, Garey et $\mathrm{al}^{6}$ and Knott et $\mathrm{al}^{7}$ demonstrated associations of obesity with longer LOS after appendectomy. Those studies also reported longer operative times, increased postoperative analgesics, and worse outcomes in obese appendectomy patients.

Regarding pediatric patients undergoing appendectomy, obesity has been associated with longer surgeries, longer hospital stays, and increased postoperative infections when compared to nonobese children. ${ }^{12,13}$ However, we found no significant increase in LOS in our pediatric population because of obesity, a finding that agrees with Blanco et al who found that obesity in general did not contribute to increased LOS or postoperative infections in a pediatric population. ${ }^{14}$ Michailidou et al showed significantly longer operative times in obese pediatric patients receiving appendectomy vs nonobese pediatric patients. ${ }^{8}$ However, that study showed no increase in pediatric postoperative complication rate after 30 days and concluded that obesity is not an independent risk factor for postoperative complications following laparoscopic appendectomy.

Our study had several limitations, including its small sample size and retrospective nature. LOS and related metrics were the primary variables of this investigation, and the time durations obtained from electronic medical record charting are prone to administrative and charting errors in the hours of time spent in the hospital. BMI is an imperfect tool for determination of obesity because it does not evaluate body type. We used a BMI $\geq 30 \mathrm{~kg} / \mathrm{m}^{2}$ to define the obese group. The study of subsets such as overweight (BMI $\left.25-29 \mathrm{~kg} / \mathrm{m}^{2}\right)$, obese $\left(\geq 30 \mathrm{~kg} / \mathrm{m}^{2}\right)$, severely obese $\left(\geq 35 \mathrm{~kg} / \mathrm{m}^{2}\right)$, and morbidly obese $\left(\geq 40 \mathrm{~kg} / \mathrm{m}^{2}\right)$ was not practical given our small sample size. The reason for the significantly longer admission time for adult patients with comorbidities is unclear. Contributing factors may have included delayed diagnosis of appendicitis given comorbidities confounding the clini- cal presentation, preoperative optimization, or both; however, these factors were not objectively assessed. Although others have reported obesity-related longer operative times and higher rates of postoperative infections, ${ }^{12,13}$ we did not assess for obesity-related longer operative times, which is a limitation.

\section{CONCLUSION}

This study adds support to the body of literature indicating that obesity is not a risk factor for a prolonged LOS after appendectomy. We noted no apparent change in the postoperative LOS in patients who spent lengthened inpatient time preoperatively, suggesting that prolonged overall LOS can be mitigated by adequate optimization before surgery in at-risk patients.

\section{ACKNOWLEDGMENTS}

Dr Ballard received salary support from National Institutes of Health TOP-TIER grant T32-EB021955 during the study period. Otherwise, the authors have no financial or proprietary interest in the subject matter of this article.

\section{REFERENCES}

1. Peery AF, Crockett SD, Murphy CC, et al. Burden and cost of gastrointestinal, liver, and pancreatic diseases in the United States: update 2018. Gastroenterology. 2019;156(1): 254-272.e11. doi: 10.1053/j.gastro.2018.08.063

2. Akinyemiju T, Meng Q, Vin-Raviv N. Association between body mass index and in-hospital outcomes: analysis of the nationwide inpatient database. Medicine (Baltimore). 2016;95(28):e4189. doi: 10.1097/MD.0000000000004189

3. Lewis O, Ngwa J, Kibreab A, Phillpotts M, Thomas A, Mehari A. Body mass index and intensive care unit outcomes in African American patients. Ethn Dis. 2017;27(2):161-168. doi: 10.18865/ed.27.2.161

4. Towfigh S, Chen F, Katkhouda N, et al. Obesity should not influence the management of appendicitis. Surg Endosc. 2008;22(12):2601-2605. doi: 10.1007/s00464-008-9847-6 
5. Witt CE, Goldin AB, Vavilala MS, Rivara FP. Effect of body mass index percentile on pediatric gastrointestinal surgery outcomes. J Pediatr Surg. 2016;51(9):1473-1479. doi: 10.1016/j.jpedsurg.2016.02.085

6. Garey CL, Laituri CA, Little DC, Ostlie DJ, St Peter SD. Outcomes of perforated appendicitis in obese and nonobese children. J Pediatr Surg. 2011;46(12):2346-2348. doi: 10.1016/j.jpedsurg.2011.09.024

7. Knott EM, Gasior AC, Holcomb GWIII, Ostlie DJ, St Peter SD. Impact of body habitus on single-site laparoscopic appendectomy for nonperforated appendicitis: subset analysis from a prospective, randomized trial. J Laparoendosc Adv Surg Tech A. 2012;22(4):404-407. doi: 10.1089/lap.2012.0056

8. Michailidou M, Sacco Casamassima MG, Goldstein SD, et al. The impact of obesity on laparoscopic appendectomy: results from the ACS National Surgical Quality Improvement Program pediatric database. J Pediatr Surg. 2015;50(11):1880-1884. doi: 10.1016/j.jpedsurg.2015.07.005

9. Singer M, Deutschman CS, Seymour CW, et al. The third international consensus definitions for sepsis and septic shock (sepsis-3). JAMA. 2016;315(8):801-810. doi: 10.1001/jama.2016.0287

10. Flegal KM, Kruszon-Moran D, Carroll MD, Fryar CD, Ogden CL. Trends in obesity among adults in the United States, 2005 to 2014. JAMA. 2016;315(21):2284-2291. doi: 10.1001/jama.2016.6458

11. Ballard DH, Raptis CA, Guerra J, et al. Preoperative CT findings and interobserver reliability of Fournier gangrene. AJR Am J Roentgenol. 2018;211(5):1051-1057. doi: 10.2214/AJR.18.19683

12. Deugarte DA, Stark R, Kaji AH, Yaghoubian A, Tolan A, Lee SL. Obesity does not impact outcomes for appendicitis. Am Surg. 2012;78(2):254-257.

13. Lee SL, Stark R, Yaghoubian A, Shekherdimian S, Kaji A. Does age affect the outcomes and management of pediatric appendicitis? J Pediatr Surg. 2011;46(12):2342-2345. doi: 10.1016/j.jpedsurg.2011.09.030

14. Blanco FC, Sandler AD, Nadler EP. Increased incidence of perforated appendicitis in children with obesity. Clin Pediatr (Phila). 2012;51(10):928-932. doi: 10.1177/0009922812441659

This article meets the Accreditation Council for Graduate Medical Education and the American Board of Medical Specialties Maintenance of Certification competencies for Patient Care and Medical Knowledge.

(C2021 by the author(s); licensee Ochsner Journal, Ochsner Clinic Foundation, New Orleans, LA. This article is an open (c) (i) access article distributed under the terms and conditions of the Creative Commons Attribution (CC BY) license (creativecommons.org/licenses/by/4.0/legalcode) that permits unrestricted use, distribution, and reproduction in any medium, provided the original author(s) and source are credited. 